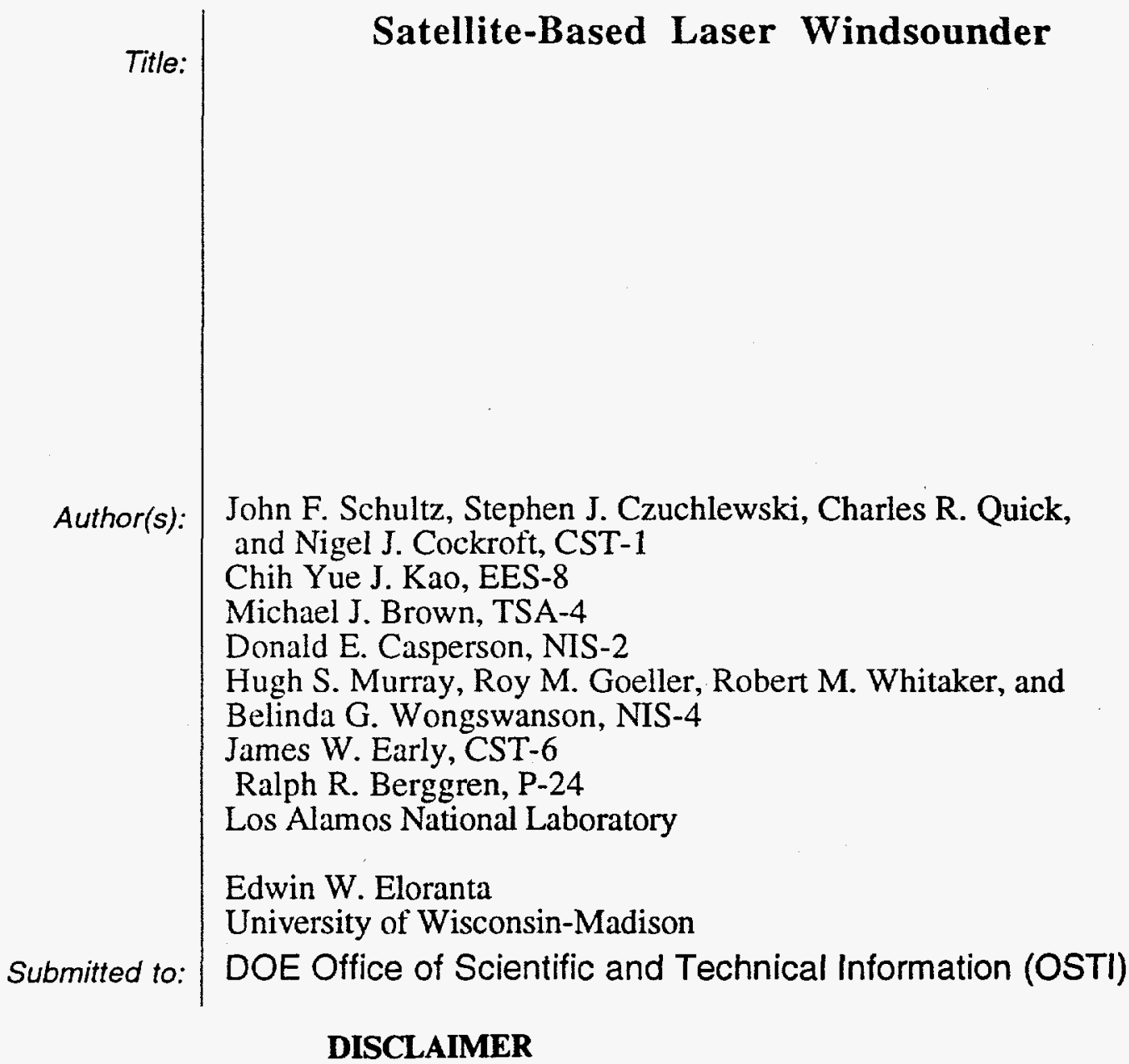

This report was prepared as an account of work sponsored by an agency of the United States Government. Neither the United States Government nor any agency thereof, nor any of their employees, makes any warranty, express or implied, or assumes any legal liability or responsibility for the accuracy, completeness, or usefulness of any information, apparatus, product, or process disclosed, or represents that its use would not infringe privately owned rights. Reference herein to any specific commercial product, process, or service by trade name, trademark, manufacturer, or otherwise does not necessarily constitute or imply its endorsement, recommendation, or favoring by the United States Government or any agency thereof. The views and opinions of authors expressed herein do not necessarily state or reflect those of the United States Government or any agency thereof.

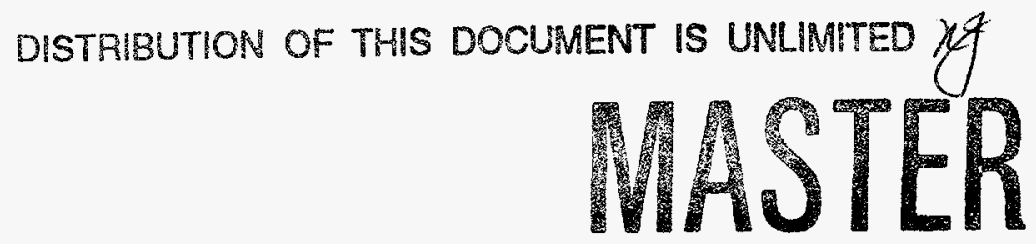

Los Alamos National Laboratory, an affirmative action/equal opportunity employer, is operated by the University of Califomia for the U.S. Department of Energy under contract W-7405-ENG-36. By acceptance of this article, the publisher recognizes that the U.S. Govemment retains a nonexclusive, royattyfree license to publish or reproduce the published form of this contribution, or to allow others to do so, for U.S. Government purposes. Los Alamos National Laboratory requests that the publisher identify this anticle as work pertormed under the auspices of the U.S. Department of Energy. Los Alamos National Laboratory strongly supports academic freedom and a researcher's right to publish; as an institution, however, the Laboratory does not endorse the viewpoint of a publication or guarantee its technical correctness. 


\section{DISCLAMMER}

Portions of this document may be illegible in electronic image products. Images are produced from the best available original document. 


\title{
Satellite-Based Laser Windsounder
}

\author{
John F. Schultz*, Stephen J. Czuchlewski, Charles R. Quick, Nigel J. Cockroft, \\ James W. Early, Chih Yue J. Kao, Michael J. Brown, Donald E. Casperson, \\ Hugh S. Murray, Roy M. Goeller, Robert M. Whitaker, \\ Belinda G. Wongswanson, and Ralph R. Berggren \\ Los Alamos National Laboratory \\ Edwin W. Eloranta \\ University of Wisconsin-Madison
}

\begin{abstract}
This is the final report of a one-year, Laboratory-Directed Research and Development (LDRD) project at the Los Alamos National Laboratory (LANL). The project's primary objective is to determine the technical feasibility of using satellite-based laser wind sensing systems for detailed study of winds, aerosols, and particulates around and downstream of suspected proliferation facilities. Extensive interactions with the relevant operational organization resulted in enthusiastic support and useful guidance with respect to measurement requirements and priorities. Four candidate wind sensing techniques were evaluated, and the incoherent Doppler technique was selected. A small satellite concept design study was completed to identify the technical issues inherent in a proof-of-concept small satellite mission. Use of a Mach-Zehnder interferometer instead of a Fabry-Perot would significantly simplify the optical train and could reduce weight, and possibly power, requirements with no loss of performance. A breadboard Mach-Zehnder interferometer-based system has been built to verify these predictions. Detailed plans were made for resolving other issues through construction and testing of a ground-based lidar system in collaboration with the University of Wisconsin, and through numerical lidar wind data assimilation studies.
\end{abstract}

\section{Background and Research Objectives}

Detection and identification of effluents resulting from nuclear, biological, and chemical (NBC) weapons manufacturing and handling is critical to the success of the international arms control program. At present, much of the national technical capability for detecting proliferation activities rests on deployment of effluent sampling systems, and a space-based wind, aerosol, and particulate detection system would be highly useful for positioning these systems downwind from suspected facilities or activities. On the battlefield, wind data is required to predict the transport of chemical and biological warfare (CBW) agents, radioactive debris from nuclear strikes, and debris from the destruction of

\footnotetext{
*Principal Investigator, e-mail: jschultz@lanl.gov
} 
NBC production and storage facilities. Wind data is also used to enhance the accuracy of ballistic projectiles. This project's primary research objectives are therefore to understand the requirements for wind measurements made in support of detecting and countering NBC proliferation, and to study the feasibility of space- and aircraft-based systems for these purposes.

In addition to the national security applications, global tropospheric wind patterns are the most important factor in global weather and climate systems. At present, detailed understanding and ability to predict weather and climate are severely hampered by the fact that tropospheric wind measurements are unavailable over two thirds of the earth's surface, and are inadequate in most regions where they are available. Economic studies [1] have shown that modest improvements in the accuracy of weather forecasts would yield tremendous economic benefits. In a recent meteorology experiment [2], the incorporation of sparse wind, temperature, and humidity data which was collected during a single aircraft flight over the Gulf of Alaska yielded substantial improvements in the accuracy of weather forecasts for North America, and the wind data was found to have much greater impact than the other quantities which were measured. In addition, a satellite-based laser windsensing system could be used for a wide variety of other scientific, practical, and military purposes. Among these are measurement and tracking of volcanic emissions, location and characterization of nuclear bursts through elastic backscatter from their plumes, identification of ship tracks, and identification and targeting of ballistic missiles and launchers through plume and hard body tracking.

To date, coherent Doppler lidar wind measurement techniques at mid-IR wavelengths and incoherent Doppler wind measurement techniques at near UV and near IR wavelengths have been considered for the global meteorology applications[1,3-8]. One technical objective of this study was to evaluate the suitability of existing wind-sensing techniques for the national security applications, with emphasis on detecting and countering NBC proliferation. Other technical objectives were to examine the feasibility of a small satellite proof-of-concept demonstration for the largest possible subset of applications discussed above, to identify the major technical issues, to devise a plan for addressing these technical issues, and to initiate experimental work.

\section{Importance to LANL's Science and Technology Base and National R\&D Needs}

Lidar research is a rapidly growing field with myriad civilian and national security applications. A few examples which involve wind sensing and are pertinent to this project include environmental studies, meteorology, aircraft safety, the accuracy of projectiles, 
bombs, and parachute drops, and predicting the dispersal of effluents from the production of weapons of mass destruction, chemical and biological warfare agents on the battlefield, and debris from nuclear explosions and attacks on production facilities. For some of these applications, lidar is an operational tool, and the development of improved lidar techniques and technologies is the focus of the research, while for other applications, lidar is a critical tool used in support of other research objectives. In either case, improved competence in advanced lidar technology is important to maintaining and enhancing Los Alamos' science, technology, and programmatic base. This LDRD project will expand both the scope and the magnitude of the Laboratory's involvement in lidar and related research.

Within the national security sector, national needs for detecting and countering proliferation activities are the primary focus of this project. Wind sensing is of interest to counterproliferation because it allows accurate prediction of chemical and biological agent dispersal on the battletield as well as prediction of the dispersal of the debris from strikes against facilities that are producing weapons of mass destruction. Wind, and perhaps water vapor and temperature sensing, can also contribute to proliferation detection by improving the positioning and interpretation of sample collection devices and point sensors.

Within the civilian sector, wind measurement is of great interest to NASA's Earth Observing System program, and has already been the subject of major investments. Microand meso-scale meteorology is of great interest to a wide variety of environmental, biological, and agricultural research activities, and when used in conjunction with lidar systems, may be a key to full utility of lidar systems for the proliferation detection and counterproliferation applications listed above.

Improving the national capability to detect and counter proliferation of weapons of mass destruction through the development of satellite and aircraft-based wind measurement techniques is a direct contribution to the Laboratory and DOE mission of reducing the nuclear danger.

\section{Scientific Approach and Accomplishments}

At the beginning of this project, a series of technical meetings with the operational organization responsible for effluent collection was arranged to discuss their needs for wind data, measurement requirements, and ideas for improving wind measurement capabilities. The operational organization was highly supportive of our ideas; two regimes of interest were identified, and the measurement requirements outlined in the next paragraph were identified.

Collection of effluents with long atmospheric lifetimes, which can be identified in very low concentration samples, is usually done at great distances from the suspected 
activity in order to allow the plume to disperse over wide areas, thus increasing the chances of obtaining a sample with coarse collector positioning. To support the coarse positioning, wind data with large spatial coverage (1000s of $\mathrm{km} \mathrm{x} 1000 \mathrm{~s}$ of $\mathrm{km}$ ) and coarse spatial and temporal resolution (100s of $\mathrm{km}$ and days) that represent average wind fields associated with continental-scale circulation features is required. This is available from routine weather balloon (rawindsonde) releases in highly developed areas of the world. However, rawindsonde stations are sparse to nonexistent over the oceans and many land masses of critical importance to proliferation detection, rawindsonde data is poorly representative of the large-scale wind motions of interest, and dissemination of rawindsonde data is under local control and thus susceptible to countermeasures. For these reasons, the operational user considers satellite-based wind measurements with global coverage on a two- to threeday time scale, horizontal resolution of $100 \mathrm{~s}$ of $\mathrm{km}$, and vertical resolution and coverage of 1 and $10 \mathrm{~km}$ (hereafter referred to as global wind measurements) to be the top priority. For effluents that have short atmospheric lifetimes or that cannot he identified in low concentration samples, it is necessary to position sampling systems close to the source, which requires highly accurate transport prediction over short distances. This requires either continuous wind measurement with spatial coverage matching distances from the source to the sampler and sub-kilometer spatial resolution, or measurements with perhaps greater coverage, but much sparser spatial and temporal resolution used in conjunction with meteorological modeling.

Given the high probability of political constraints on access to areas in which proliferation activities are taking place, modeling is probably required. To date, meteorologists have never had adequate measured data with which to check their models, and so the measurement requirements for accurate regional scale modeling are not well known. However, it is thought that the global wind measurements discussed above are required to provide boundary conditions, and that wind, temperature, and humidity measurements with approximately 1 to $10 \mathrm{~km}$ spatial resolution, $100 \mathrm{~km}$ spatial coverage around the facility of interest, 1 to 3 day temporal resolution, and 6 to 12 month temporal coverage is required for model initialization, checking, and adjustment. The temporal resolution and temporal/spatial coverage requirements are roughly compatible with the orbital characteristics of a LEO satellite, but probably exceed what could be done with covert ground or aircraft - based systems.

Based on these measurement requirements and priorities, the global wind measurement mission was selected for detailed study. Another consideration is that the first lidar wind-measurements satellite should be small and inexpensive to reduce the risk and development timeline. However, generating high spatial resolution meteorology data 
from a satellite-based lidar requires burst-mode power output and pointing control, which lie beyond the capabilities of a small satellite.

Having identified the mission and measurement requirements, the existing literature on lidar wind measurement techniques was carefully read and verified through independent calculations, where possible, to begin establishing the capabilities and risks of each technique. The outcome of this process was selection of a technique, known as the incoherent Doppler technique, in which the Doppler shift in near UV laser light scattered from atmospheric aerosols and molecules entrained in the wind field is measured with an optical interferometer [3, 5-7]. Despite their relative maturity for ground and aircraft-based applications, we rejected heterodyne Doppler techniques (in which the Doppler shift in midIR laser light scattered in the atmosphere is detected through heterodyne mixing with a local oscillator laser) for the following reasons: a) excessive laser power requirements for measurements at altitudes above the planetary boundary layer (approximately $1 \mathrm{~km}$ ), b) difficult tolerances for alignment between the local oscillator and the receiver, and c) low potential for measuring the other meteorological quantities of interest for regional transport prediction with the same lidar due to the mid-IR wavelengths at which heterodyne Doppler measurements are possible [7-8].

After the incoherent Doppler lidar technique was selected, a conceptual design study was initiated to examine the feasibility of a proof-of-concept global wind-measurement mission aboard a Pegasus XL class (small) satellite [11]. Following work that was done at the University of Michigan $[3,6,9,10]$, the instrument design was based on use of a Fabry-Perot interferometer (Figs. 1 and 2) for measuring the Doppler shift. Specifications for this point design are given in Table 1. The resulting conceptual design was determined to fit the envelope of Pegasus XL mission (Fig. 3), but with little margin in power consumption and slightly negative margin in weight $(25 \mathrm{lb}$.), largely due to the inefficiency of the Fabry-Perot.

Details of the lidar system analysis and modeling are presented in Ref. 12. Figure 4 indicates the predicted accuracy of wind-velocity measurements as a function of altitude with a $1-\mathrm{km}$ range resolution and with a Fabry-Perot interferometer. The main conclusion is that under most atmospheric conditions accurate wind measurements ( $1-2 \mathrm{~m} / \mathrm{s}$ accuracy) can be obtained with 100-J of laser energy. (A 14-sec sample time is required to transmit $100-\mathrm{J}$ from a 7-W laser, whereas the satellite is overhead of any ground point for approximately $100 \mathrm{sec}$.) Wind accuracy can be further improved by averaging over larger vertical regions.

Among the issues identified for further study were: the matching of satellite optical scanning patterns and laser duty cycles for optimum use of the available laser power; 
satellite scanning mechanisms, pointing knowledge requirements, values of the aerosol backscatter coefficient at 355-nm, and wind-field sampling/data-averaging algorithms.

At the end of this research period, a promising alternative technology (a MachZehnder interferometer) was identified, which would overcome a number of the limitations of the interferometer employed in the initial point-design described above. The advantages of replacing the inefficient Fabry-Perot in our wind-sensing systems with a Mach-Zehnder include:

- Reduced tolerances on optical figure and alignment.

- A wide field-of-view that permits the use of small diameter optics (20 $\mathrm{mm}$ ) and minimizes the impact of speckle from the target.

- Simple detector system due to a straight fringe pattern instead of a circular one.

- High throughput ( $>50 \%$ from telescope through detector).

- Greatly-reduced requirements on laser stability, interferometer stability and interferometer tunability.

Each of these lead to a significantly simpler optical system and improved performance for satellite-based wind-sensing instruments. A breadboard Mach-Zehnder interferometerbased system was built (Fig. 5) and demonstrated the expected qualitative performance. Also at the end of this period, work has been initiated on applying a novel technique (extended Kalman filter) to the assimilation of lidar wind data into global meteorologic models [13]. Such an improved technique could significantly enhance the utility of lidar wind data.

\section{Conclusions}

The objective of this project was to determine the technical feasibility of using satellite-based, laser wind-sensing systems for detailed study of winds, aerosols, and particulates around and downstream of suspected proliferation facilities. During 1996 extensive interactions with the relevant operational proliferation-detection organization revealed that satellite-hased wind sensing lidars can contribute to long-range and regional proliferation detection, and provided enthusiastic programmatic support and useful guidance with respect to measurement requirements and priorities. Four candidate wind sensing techniques were evaluated, and the incoherent Doppler technique, which uses an interferometer to measure the Doppler shift in near-ultraviolet laser scattered from aerosols and particulates entrained in the winds, was selected. A small satellite concept design study was completed to identify the technical issues inherent in a proof-of-concept satellite 
mission appropriate to Los Alamos' technical capabilities. The major issues identified are the weight and power consumption of a Fabry-Perot interferometer-based instrument, the lidar scanning pattern and pointing knowledge, and data assimilation techniques. During the study, it was determined that use of a Mach-Zehnder interferometer instead of a FabryPerot would significantly simplify the optical train and could reduce weight, and possibly power, requirements with no loss of performance. A breadboard Mach-Zehnder interferometer-hased system has been built to verify these predictions. Detailed plans have been established for resolving the other issues through construction and testing of a ground-based lidar system in collaboration with the University of Wisconsin, and through numerical data assimilation studies.

\section{Publications}

1. Czuchlewski, S.J., M.J. Brown, G.H. Nickel, C.R. Quick, J.F. Schultz, D.E. Casperson, N.J. Cockroft, Cheng Ho, G.P. Quigley, and W.C. Priedhorsky, "Preliminary Analysis of Lidar Techniques for Regional Meteorological Studies," in Gas and Chemical Lasers, Proceedings SPIE vol. 2702, R.C. Sze, ed. (SPIE, 1996) pp.52 64.

2. Czuchlewski, S.J.and R. Berggren, "Incoherent Doppler Wind-Sensing: Lidar Analysis of Aerosol and Molecular Backscatter Signals", LANL internal report (Nov. 18, 1996).

3. Kao, C.Y.J., "How Can a Single Line-of-Sight (LOS) Wind Component Measured By Space-Based Lidar Be Used In Meteorological Data Assimilation", LANL internal report (October, 1996).

\section{References}

[1]. W.E. Baker, G.D. Emmitt, F. Rohertson, R.M. Atlas, J.E. Molinari, D.A. Bowdle, J. Paegle, R.M. Hardesty, R.T. Menzies, T.N. Krishnamurti, R.A. Brown, M.J. Post, J.R. Anderson, A.C. Lorenc, J. McElroy, "Lidar-measured winds from space: a key component for weather and climate prediction ", Bull. Am. Meteor. Soc.. 76, 869-888 (1995).

[2]. S.J. Lord, B.B. Katz, and G. Frederick, "The Impact on Synoptic-Scale Forecasts Over the United Sates of Dropwindsonde Observations Taken in the Northeast Pacific Ocean", in Minutes of the NOAA Working Group On Space-Based Lidar Winds, W. Baker ed. (Daytona, February 1996).

[3]. V.J. Abreu, "Wind measurements from an orbital platform using a lidar system with incoherent detection: An analysis," Appl. Opt. 18, 2992-2997, 1979.

[4]. Menzies, R. T., "Doppler lidar atmospheric wind sensors: A comparative performance evaluation for global measurements applications," Appl. Opt. 25, 2546-2553, 1986.

[5]. Rees, D., and I. S. McDermid, "Doppler lidar atmospheric wind sensor: Reevaluation of a 355-nm incoherent Doppler lidar," Appl. Opt. 29, 4133-4144, (1990). 
[6]. W.R. Skinner and P.B. Hays, "A Comparative Study of Coherent and Incoherent Doppler Lidar Techniques", Univ. of Mich. report for NASA (June 3, 1994).

[7]. S.J. Czuchlewski, M.J. Brown, G.H. Nickel, C.R. Quick, J.F. Schultz, D.E. Casperson, N.J. Cockroft, Cheng Ho, G.P. Quigley, and W.C. Priedhorsky, "Preliminary Analysis of Lidar Techniques for Regional Meteorological Studies," in Gas and Chemical Lasers, Proceedings SPIE vol. 2702, R.C. Sze, ed. (SPIE, 1996) pp.52 64.

[8]. D.P. Greenwood, C.A. Primmerman, C. Freed, R.M. Heinrichs, R. Kramer, J.R. Liftsitz, D.E. Weidler, "Laser Atmospheric Wind Sounder (LAWS) Technology Assessment", MIT-Lincoln Lab report \# NOAA-9 (February 23, 1994).

[9]. P. B. Hays, V. J. Abreu, M. E. Dobbs, D. A. Gell, H. J. Grassl, and V. R. Skinner, "The High-Resolution Doppler Imager on the Upper Atmosphere Research Satellite," J. Geophys. Res. 98, 10,713 - 10,723 (1993).

[10]. M.J. McGill, W.R. Skinner, and T.D. Irgang, "Analysis technique for the recovery of winds and backscatter coefficients from a multiple channel incoherent Doppler lidar", Appl. Opt. (1996), in press.

[11]. Schultz, J. F., S.J. Czuchlewski, H.S. Murray et al., "Satellite-Based Remote Wind Sensing", LANL briefing for US Dept. of Energy (NN-20) (May 14, 1996).

[12]. Czuchlewski, S.J.and R. Berggren, "Incoherent Doppler Wind-Sensing: Lidar Analysis of Aerosol and Molecular Backscatter Signals", LANL internal report (Nov. 18, 1996).

[13]. Kao, C.Y.J., "How Can a Single Line-of-Sight (LOS) Wind Component Measured By Space-Based Lidar Be Used In Meteorological Data Assimilation", LANL internal report (October, 1996). 
Table 1. Specifications for lidar analysis of Zephyrus wind-sensing satellite.

\begin{tabular}{ll}
\hline Parameter & Specification \\
\hline & \\
$\begin{array}{l}\text { Satellite: } \\
\text { altitude }(\mathrm{km})\end{array}$ & 450 \\
nadir angle (deg) & 30 \\
& \\
$\begin{array}{l}\text { Laser: } \\
\text { wavelength (nm) }\end{array}$ & 355 \\
bandwidth (MHz) & $<25$ \\
output transmitted (W) & 7 \\
& \\
Telescope: & \\
primary: diameter (cm) & 100 \\
FOV (mrad) & 0.12 \\
& \\
& \\
$\begin{array}{l}\text { Optics \& Detector: } \\
\text { transmission* (\%) } \\
\text { interferometers } \\
\text { detector Q.E. (\%) }\end{array}$ & 10 \\
\# of detector channels & 60 \\
\hline
\end{tabular}

* excluding interferometer 


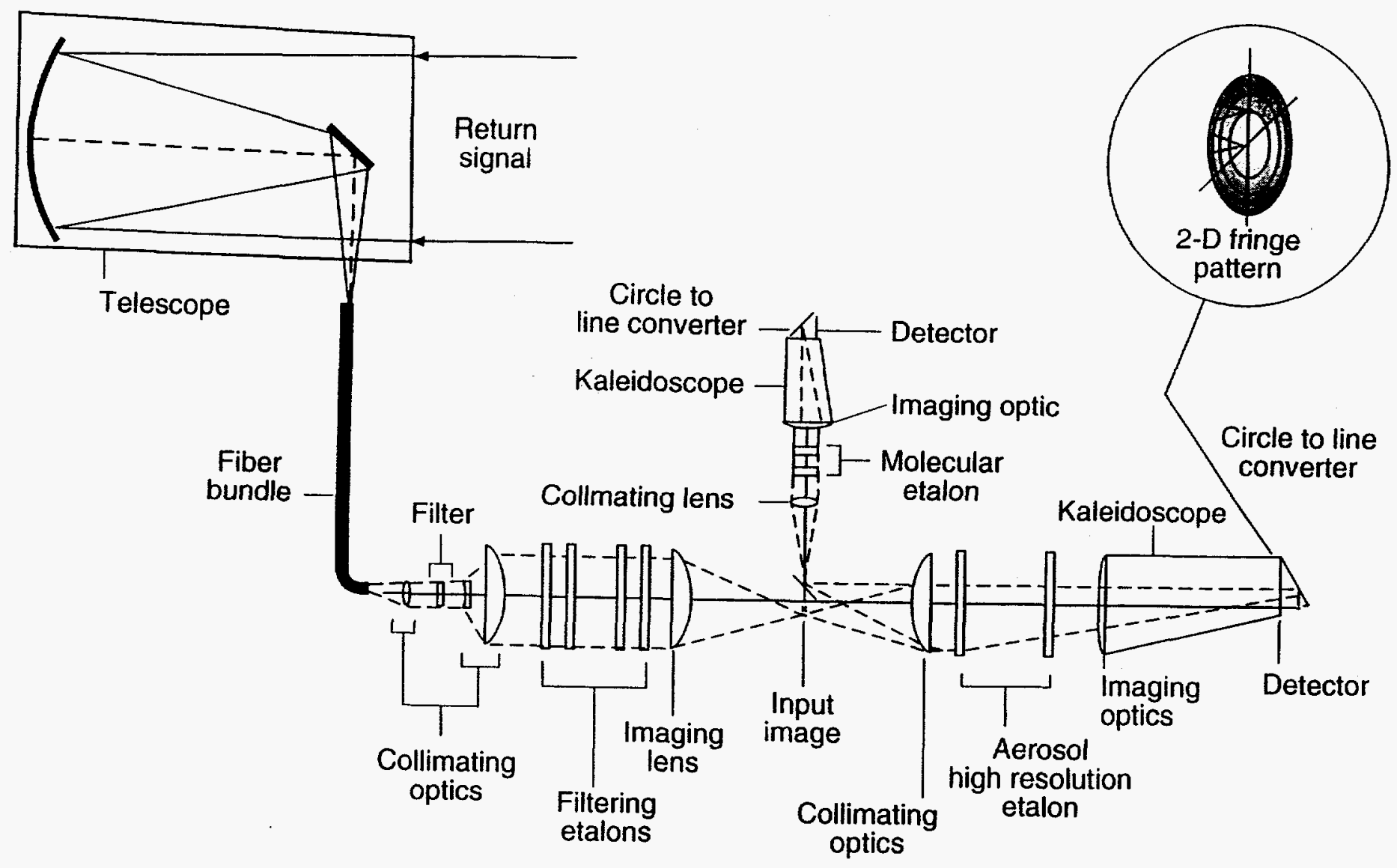

Figure 1: The layout for the complete optical train for an incoherent Doppler wind sensing system. The system can be simplified by replacing the Fabry-Perot Interferometer with a Mach-Zehnder Interferometer. 


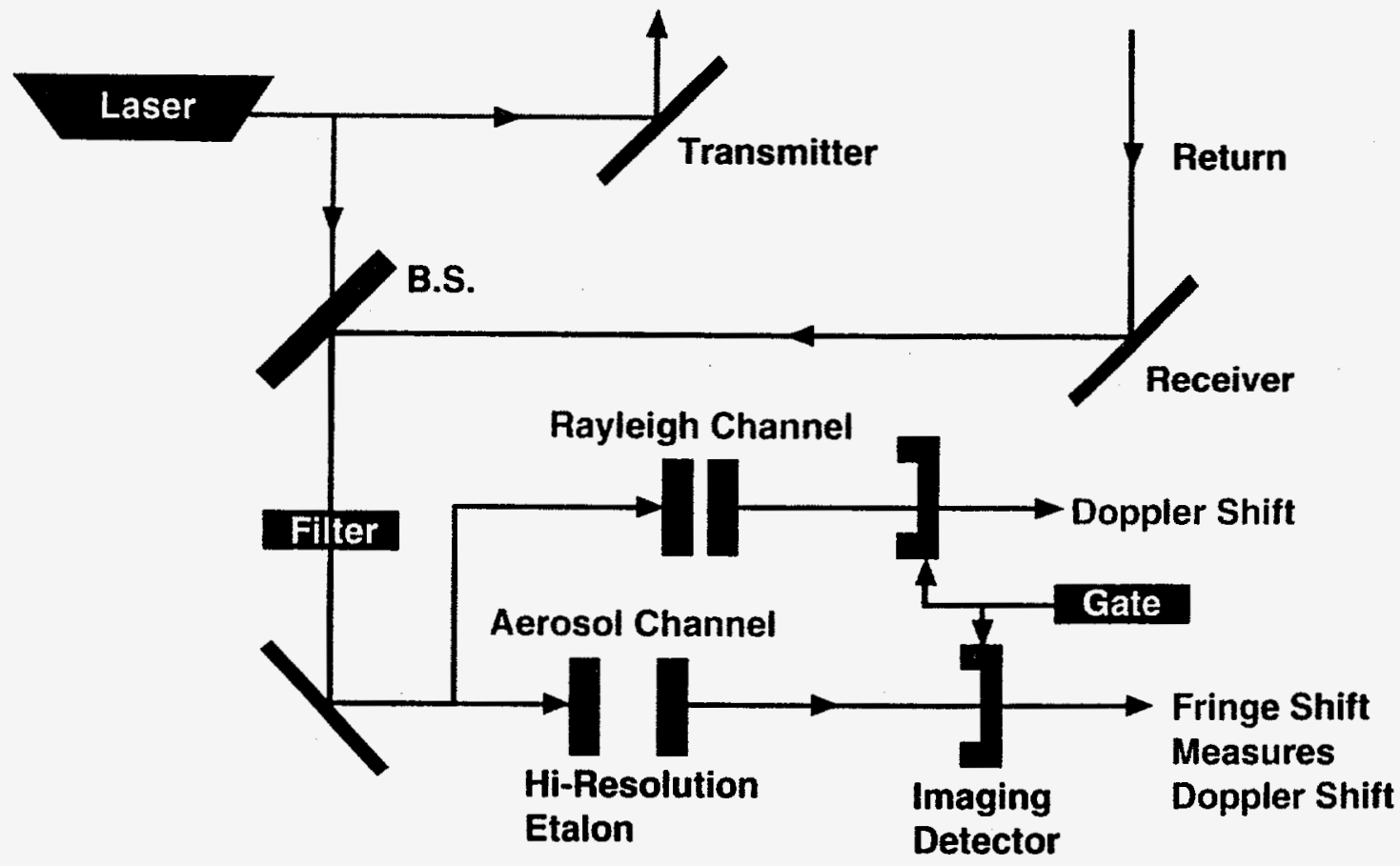

Sequential measure of reference and return beam

Figure 2: Schematic of an incoherent Doppler wind sensor, employing a Fabry-Perot Interferometer. This two-channel system can detect both aerosol and Rayleigh backscatter signals. 


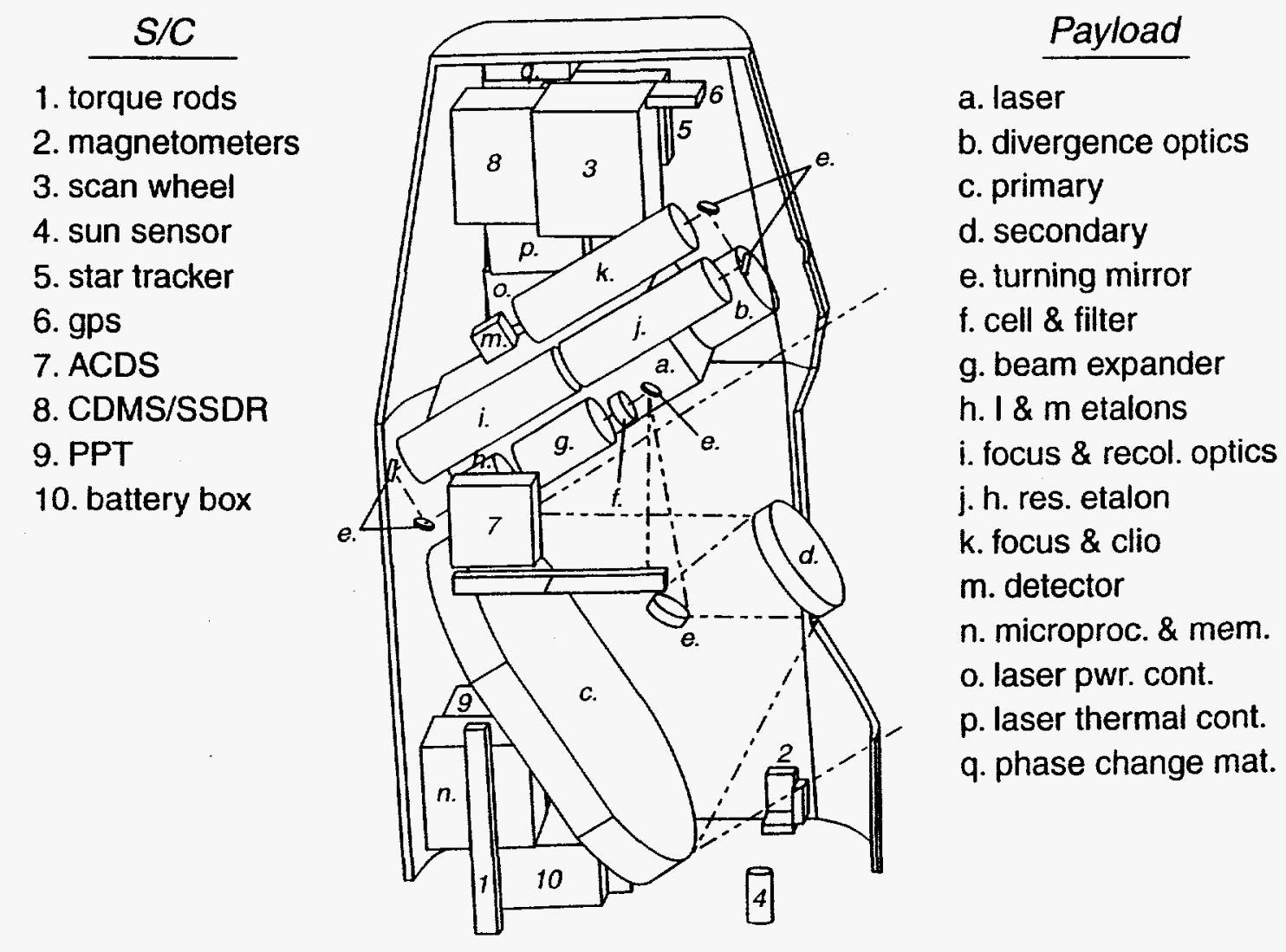

Figure 3: Layout for the complete lidar system for the original point-design. The payload fits within the envelope of the small Pegasus satellite. 


\section{Wind Accuracy vs. Altitude}

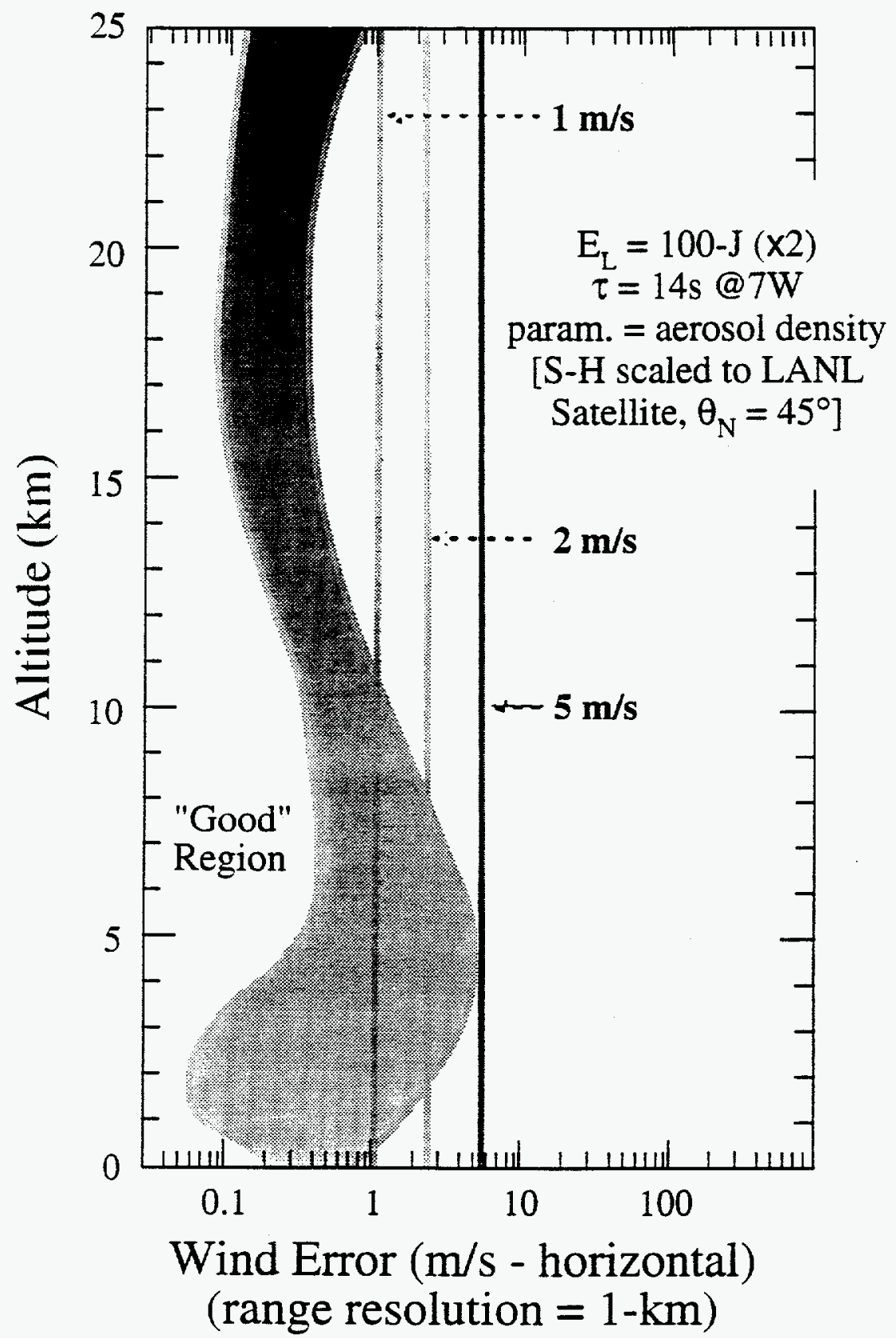

Figure 4: Accuracy of wind velocity measurements achieved as a function of altitude for a range of atmospheric aerosol concentrations. For a nominal 100-J of transmitted laser energy, accuracies of $1-2 \mathrm{~m} / \mathrm{s}$ are achieved most of the time with the point-design (FabryPerot ) system. System models are described in Refs. 6 and 12. 


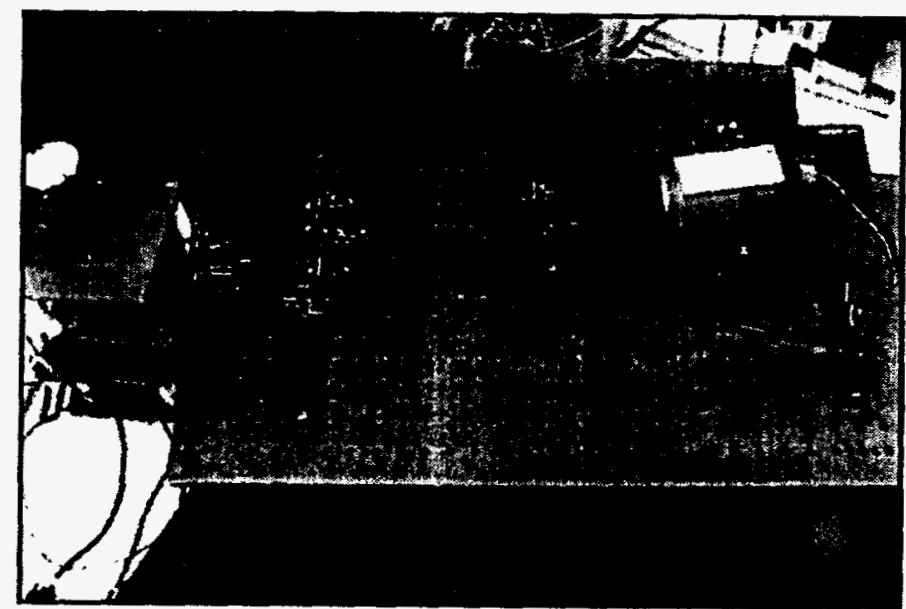

\section{Mach-Zehnder} Interferometer

- OPD of $800 \mathrm{~mm}$ on a $200 \times 800 \mathrm{~mm}$ table

- Fringes were stable except for atmospheric turbulence drift

- "Target" was a spinning wheel

- Velocity of $\sim 6 \mathrm{~m} / \mathrm{s}$ produced an observable fringe shift; sensitivity limited by the drift of fringes caused by the atmosphere

Figure 5: Breadboard system that was constructed at LANL to test qualitative performance of the Mach-Zehnder interferometer Doppler-shift detector. 